\title{
AGEN BRANCHLESS BANKING UNTUK MENCAPAI MASYARAKAT BANKABLE
}

\author{
Tetty Yuliaty \\ FEB. Universitas Sumatera Utara Medan \\ (tettyjuliaty@gmail.com) \\ Arlina Nurbaity Lubis \\ FEB. Universitas Sumatera Utara Medan
}

\begin{abstract}
The potential of Branchless banking is good enough for revolution of payment system in the emerging markets. Which aims to expand financial services to unbanked communities and provide a platform to contact MSMEs to the global economy can be achieved. Bank Indonesia (BI) targets the percentage of people reaching bankable services to reach 50\% by 2019. By the end of 2014 , the new bankable group reaches 36\%. Meanwhile, as many as $64 \%$ are unreached groups of services from banks (unbankable), now our society tend to have mind-minded economy mindset. For that, need an increase from the side of savings. Digital financial services (LKD) such as Branchless Banking initiated by Bank Indonesia may be part of this intermediation. Some of the reasons that make the unbankable group exist, ie they do not understand how to open an account. In addition, people may also prefer to save themselves, shy with the formalities, or they are no money. Branchless Banking Agent as one of the elements in the implementation of Branchless Banking very need to be studied existence. To assist this research, and also use primary data needed and secondary in the implementation, in-depth interviews, observation and other in reviewing this qualitative research. The purpose of this study was to determine whether branchless banking agents were able to reach the bankable community. Methods of data collection in this study are, documentation studies, Direct observation, Indepth interview Open Questions, as well as provide a question sheet to the respondents and other sources. Qualitative Data Analysis Method used in this research is successive approximation method. The results of this study indicate that Agent Banking is able to become one of the elements in achieving Bankable
\end{abstract}


society, where with its existence, its proximity and intensity with unbanked communities, can slowly increase bankable society.

Keyword: branchless banking, financial inclusion, agent banking

\section{A. Pendahuluan}

Peluncuran Branchless Banking sangat disambut antusias karena pemerintah menyadari Indonesia termasuk salah satu negara dengan kondisi literasi keuangan masyarakatnya yang masih rendah. Menurut Global Financial Inclusion Index 2011 mengungkapkan bahwa hanya sebesar 19,6 persen jumlah orang dewasa yang memiliki account di bank. Sementara menurut hasil Survei Neraca Rumah Tangga yang dilakukan Bank Indonesia pada 2010 menyebutkan bahwa 62 persen rumah tangga tidak memiliki tabungan sama sekali. Fakta ini sejalan pula dengan hasil studi World Bank tahun 2010 yang menyatakan bahwa hanya separuh dari penduduk Indonesia yang memiliki akses ke sistem keuangan formal. Artinya ada lebih dari setengah penduduk yang tidak punya akses ke lembaga keuangan formal sehingga membatasi kemampuan masyarakat untuk terhubung dengan kegiatan produktif yang seharusnya baik dilakukan. Berdasarkan hasil survei tersebut, terlihat bahwa Indonesia termasuk yang rendah. Bahkan dalam komponen investasi, posisi Indonesia adalah yang terbelakang dari seluruh negara Asia Pasifik. Salah satu faktor yang mengakibatkan rendahnya literasi tersebut adalah kurangnya antusias masyarakat terhadap produk-produk jasa keuangan. Hal ini dapat disebabkan oleh kondisi geografis dari beberapa wilayah di Indonesia yang sulit untuk dijangkau.

Bukan hanya itu, banyaknya masyarakat Indonesia khususnya yang terletak pada daerah-daerah remote area dan termasuk dalam golongan ekonomi menengah ke bawah memiliki persepsi bahwa bank bukanlah sesuatu untuk mereka. Mereka justru dalam keseharian bersentuhan secara tidak langsung dengan layanan keuangan (financial service) yang juga dilakukan bank. Namun karena persepsi, mereka cenderung melakukannya dengan lembaga yang bukan bank antara lain koperasi dan perorangan. Sehingga tidak jarang mereka akan sering berhadapan dengan transaksi kepada para rentenir. Termasuk masih banyaknya 
kalangan unbanked people juga dapat diakibatkan oleh rendahnya literasi keuangan yang dimiliki oleh sebagian besar masyarakat. Mereka masih memiliki pola pikir bahwa berhubungan dengan perbankan adalah suatu hal yang rumit dan kurang praktis, ditambah pula dengan kewajiban untuk mengisi administratif serta biaya-biaya yang menurut mereka adalah biaya yang seharusnya tidak perlu dikeluarkan. Pemikiran seperti itu yang mengakibatkan mereka untuk memilih tidak berhubungan dengan perbankan atau menjadi kalangan unbanked people. Dengan adanya program Branchless Banking yang melibatkan agen banking dalam implementasi transaksi perbankan, akan mampu menjangkau masyarakat awam yang selama ini tidak mau berhubungan dengan bank menjadi mudah, sehingga tujuan pemerintah untuk mencapai masyarakat bankable akan terealisasi.

Bank Indonesia (BI) menargetkan presentase masyarakat yang terjangkau layanan bank (bankable) dapat mencapai 50\% pada 2019. Sampai akhir tahun lalu tahun2014, porsi masyarakat golongan bankable baru mencapai $36 \%$. Sementara itu, sebanyak $64 \%$ merupakan golongan yang tidak terjangkau layanan dari bank (unbankable), saat ini masyarakat kita cenderung memiliki pola pikir cash minded economy. Oleh sebab itu, transaksi yang ada di Tanah Air masih lebih banyak menggunakan uang tunai. Untuk itu, perlu peningkatan dari sisi tabungan. Layanan keuangan digital (LKD) yang BI inisiasi dapat menjadi bagian intermediasi hal tersebut, seperti Branchless Banking.

Beberapa alasan yang membuat golongan unbankable itu ada, yakni mereka tidak mengerti cara membuka rekening. Selain itu, masyarakat juga mungkin lebih memilih menabung sendiri, sungkan dengan formalitas, ataupun mereka memang tidak ada uang. Adapun, data World Bank menunjukkan, presentase masyarakat berusia 15 tahun keatas yangbankable mencapai 36\% pada akhir 2014. Persentase itu tumbuh sebesar 16\% dibanding porsi pada 2011 yang mencapai $20 \%$.

\section{B. Pembahasan}

Penelitian yang sebelumnya direncanakan melalui FGD dengan beberapa Bank, namun karena kesibukan yang tinggi di 
masing-masing Bank, serta ketertutupan informasi dari beberapa bank yang turut menyelenggarakan program branchless banking ini, akhirnya dilakukan dengan interview, deepth interview dan direct observation, baik Bank Indonesia, OJK, BTPN serta para agen banking, nasabah dan masyarakat sekitar agen banking. Untuk memahami tentang agen banking pihak Bank BTPN secara langsung telah menunjukkan langsung bagaimana proses pendaftaran melalui branchless banking yang bisa dilakukan oleh agen banking. Bagaimana para agen banking melakukan transaksi pembukaan rekening ataupun penyetoran dan penarikan dana para nasabahnya. Dan untuk melengkapi penelitian ini, telah dilakukan survey atau penyebaran kuesioner di beberapa kecamatan di Medan seperti di kecamatan Medan Timur, kecamatan Medan Helvetia, kecamatan Medan Sunggal, kecamatan Medan Selayang, kecamatan Medan Barat, kecamatan Medan Petisah. Lokasi penelitian ini memang dikhususkan mengingat keberadaan Bank-bank umumnya banyak berada di lokasi di atas, dibanding kecamatan lainnya. Sehingga hasil jawaban mampu memberikan gambaran yang umum bagaimana layanan ini diterima masyarakat, agar penelitian ini dapat lebih akurat. Dari hasil angket ini dapat diperoleh data bahwa para responden terdiri dari masyarakat yang berbeda profesi dan status serta usia, seperti, karyawan, pemilik warung dan toko, pedagang, mahasiswa dan pelajar sekolah menengah, Ibu Rumah Tangga dan lainnya.

\section{Agen Banking}

Dari hasil penelitian ini diketahui bahwa para agen banking ini banyak berada di lingkungan perumahan yang padat penduduknya di kota Medan, dan pendapatannya menengah ke bawah, dimana pada umumnya masyarakat di sini memang belum banyak yang berhubungan dengan Bank. Seperti pada umumnya di beberapa provinsi di Indonesia, di kota Medan masyarakatnya masih belum begitu terbiasa dengan menggunakan jasa perbankan, jadi dengan adanya agen banking ini, memang memudahkan masyarakat untuk menjadi masyarakat bankable. Umumnya Para agen banking ini memiliki usaha sendiri di rumahnya atau toko. Dan nasabah dari bank yang bersangkutan, dalam hal ini BTPN, 
alasannya adalah mempermudah pengawasan, walaupun dengan syarat tertentu masyarakat umum diperbolehkan, tetapi harus menjadi nasabah bank yang bersangkutan. Kategori dari para agen banking ini relatif dewasa. Sehingga mereka memang mengenal perbankan secara baik dan hukum. Dan yang terpenting memiliki pendidikan yang cukup baik, walaupun si pengusaha tidak berpendidikan tinggi, namun keluarga yang bersangkutan memiliki pendidikan yang cukup baik. Ini berarti pemahaman tentang seluk beluk bank apalagi agen banking cukup mudah dipahami. Dari sini terlihat bahwa sebenarnya layanan Keuangan Tanpa Kantor Dalam Rangka Keuangan Inklusif (Branchless Banking) memungkinkan perbankan melakukan ekspansi bisnis dengan mengandalkan agen. Jika bank yang bersangkutan pintar mencari peluang. Karema seperti diketahui agen-agen memegang peran penting bagi bank saat melakukan ekspansi, dan bank tidak perlu membayar agen seperti pegawai bank. Agen hanya dibayar dengan sistem komisi per transaksi. Dari hasil survey ini diketahui para agen banking yang memilih BTPN di Medan, sangat percaya dengan banknya. Demikian sebaliknuya Agen banking juga adalah orang-orang yang dipercaya Bank sebagai perpanjangan tangannya, dimana semua transaksi dapat dilakukan hanya di Agen banking dan tidak perlu melalui Bank ataupun hal lainnya. Tidak heran bagaimana bank menjaga agen bankingnya dengan baik, sebagai orang yang dipercayanya agen banking menjadi ujung tombak penyebaran e-cash ini, mereka adalah orang yang terseleksi, apakah mereka adalah sosok yang tepat dan bisa dipercaya komunikasi.

Sama seperti yang dinyatakan dalam ketentuannya para agen Branchless Banking BTPN dapat melayani transaksi-transaksi dasar keuangan seperti pembukaan rekening uang elektronik, setor tunai dan tarik tunai selain membantu dalam memberikan edukasi ke masyarakat. Sementara untuk transaksi non-tunai seperti transfer uang ke nomor HP, beli pulsa HP, atau token listrik dapat dilakukan sendiri oleh pemilik rekening melalui HP. Transaksi-transaksi tersebut relatif aman karena adanya PIN (Personal Identification Number). Kendala sosial yang selama ini menyebabkan banyak orang enggan menggunakan layanan perbankan bisa diatasi. Dari hasil penelitian diketahui bahwa begitu banyak seharusnya 
fasilitas yang bisa dilakukan melalui agen banking, namun saat ini transaksi melalui agen banking yang ada di Medan masih sangat terbatas untuk pembayaran atau penarikan sejumlah tertentu, atau hanya mengisi pulsa handphone belum banyak yang menggunakan fasilitas lainnya, ini disebabkan ketidaktahuan masyarakat dan perlunya para agen banking mengingatkan nasabahnya ketika bertransaksi mengenai fasilitas yang tersedia

\section{Masyarakat Bankable}

Sesuai Undang-Undang Nomor 10 Tahun 1998 yang menjelaskan perbankan Indonesia bertujuan menunjang pelaksanaan pembangunan nasional dalam rangka meningkatkan pemerataan, pertumbuhan ekonomi, dan stabilitas nasional ke arah peningkatan kesejahteraan rakyat banyak: Maka Industri perbankan Indonesia yang masih tumbuh sehingga belum semua masyrakat bisa menjangkau atau memiliki akses kepada perbankan. Dari hasil survey dapat dilihat bahwa engingat masyarakat setempat belum menjadi masyarakat bankable, karena berbagai alasan pertimbangan sehngga mereka belum menyimpankan uangnya di bank. Agen banking bisa menjadi media untuk mencapai masyarak bankable, secara perrlahan-;lahan. Karena agen banking bisa mengajak masyarat untuk berbank secara langsung. Dengan adanya agen banking ini juga anggapan-anggapan negatif tentang bank dapat diminimalisir, karena mereka dapat langsung berhadapan dengan para agen banking jika ada yang ingin diketahui.

\section{BTPN WOW}

Hasil observasi di lapangan terlihat bahwa Bank BTPN yang merupakan salah satu bank yang menjadi pelopor implementasi branchless banking yang tercepat dan terdekat dengan masyarakat Medan, yang paling berhasil mengambil hati masyarakat, ini dilihat dari respon masyarakat yang cukup baik berasal dari lingkungan tempat dimana para agen banking berada. Pihak Bank BTPN Medan juga cukup aktif dalam menyentuh masyarakat di sekitarnya untuk menjadi nasabahnya melalui para agen banking Bank tersebut. Melalui BTPN Wow, BTPN mengembangkan layanan perbankan bagi mass market dengan memanfaatkan teknologi telepon 
genggam dan didukung jasa agen. Peran agen banking sangat penting sebagai perpanjangan tangan BTPN untuk meningkatkan jangkauan layanan kepada nasabah di seluruh pelosok Indonesia.

BTPN WOW sendiri lahir dari proses panjang, yang diawali dengan menjadi bagian dalam uji coba branchless banking yang digagas oleh Bank Indonesia pada 2013. Hal ini merupakan langkah yang sangat penting, karena dalam proses tersebut BTPN melihat secara langsung tingginya kebutuhan dan antusiasme masyarakat untuk menabung di bank, dan BTPN jeli melihat peluang yang begitu besar di depan mata. Kini Bank BTP memiliki beratus-ratus agen banking yang menyebar di kota Medan, yang berlokasi di pemukiman-pemukiman penduduk yang cukup padat jumlahnya. BTPN fokus menggarap pasar masyarakat berpenghasilan rendah serta pelaku Usaha Mikro, Kecil dan Menengah (UMKM), membuat PT Bank Tabungan Pensiunan Nasional Tbk (BTPN) meluncurkan BTPN Wow, sebuah inovasi Branchless Banking. Branchless Banking adalah Layanan Keuangan Tanpa Kantor dalam Rangka Keuangan Inklusif yang digagas Otoritas Jasa Keuangan (OJK). BTPN Wow. Jumlah masyarakat Indonesia yang belum tersentuh jasa layanan keuangan seperti transfer, menabung ataupun kredit masih tinggi.

Branchless Banking merupakan konsep revolusioner yang akan mengubah peta perilaku masyarakat Indonesia dalam bankable (berbank). Merupakan suatu kebanggaan bagi BTPN yang dipercaya menjadi salah satu pionir dalam inisiatif program ini. Fokus BTPN dalam menggarap pasar masyarakat berpenghasilan rendah serta pelaku UMKM, diyakini menjadi salah satu keunggulan BTPN dalam mengimplementasi Branchless Banking. BTPN Wow. merupakan layanan perbankan yang praktis dan terjangkau, dengan memanfaatkan teknologi telepon genggam dan didukung jasa agen sebagai perpanjangan tangan BTPN. Dengan hadirnya BTPN WOW sebagai agen bankin, masyarakat bisa menikmati berbagai layanan perbankan seperti pembukaan rekening, tarik dan setor uang melalui agen bank dengan biaya yang sangat murah, transfer dana, serta melakukan pembayaran atau pembelian. Teknologi yang digunakan juga disesuaikan dengan target nasabah, yaitu menggunakan USSD atau Unstructured Supplementary 
Services Data. Teknologi ini memungkinkan segala jenis handphone GSM (tidak harus smartphone) untuk bertransaksi, bahkan dengan sinyal minimum. Seluruh transaksi bisa dilakukan cukup dengan menekan *247\# melalui telepon genggam. Target nasabah BTPN Wow! adalah masyarakat yang belum pernah memiliki rekening bank, tetapi mereka sudah terbiasa menggunakan telepon seluler serta mengisi pulsa. Dengan begitu, bagi mereka bertransaksi menggunakan ponsel bukan hal yang terlalu rumit.

Dalam ekosistem Branchless Banking, agen memegang peranan yang sangat penting, karena agen adalah ujung tombak tempat nasabah melakukan transaksi perbankan. Agen dapat berbentuk badan hukum maupun individual, yang diseleksi berdasarkan kriteria tertentu seperti rekam jejak berbisnis, reputasi, lokasi, maupun kemampuan dan pengetahuan dari calon agen. Dengan adanya BPTN Wow sebagai agen banking dapat mendorong masyarakat semakin terbiasa dengan kebiasaan baru dalam berbank (bankable) ini.

Hasil dari penelitian ini dapat diungkap secara singkat bahwa persyaratan menjadi agen banking tidak dibatasi dan tidak sulit, siapa saja bisa menjadi agen banking, jika Bank penyelenggara bisa menjamin keberadaannya. Dan siapa saja bisa menjadi orang yang terpilih untuk menjadi agen banking, walaupun bukan nasabah bank penyelenggara, jika memiliki usaha yang cukup menjamin ketersediaan dana yang dibutuhkan bagi nasabah, dan selanjutnya akan didaftarkan menjadi nasabah bank penyelenggara. Dan nilai saldo nilah yang menjadi batasan kisaran dana yang bisa ditarik nasabah ataupun diterima. Dan bagi agen banking yang berhasil akan mendapatkan reward dari bank penyelenggara terkait. Untuk lebih lengkapnya dapat dilihat pada bank penyelenggara masingmasing dan juga harus tidak melanggar Peraturan Otoritas Jasa Keuangan, seperti yang dilakukan Bank BTPN. PT Bank Tabungan Pensiunan Nasional (BTPN) Tbk. memberikan fee atau imbalan kepada agen program Layanan Keuangan Tanpa Kantor (Branchless banking) sebesar $4 \%$ untuk setiap transaksinya.. Sebagai daya tarik untuk agen yakni keuntungan mendapatkan fee dari program Branchless Banking ini.. BTPN juga memberikan fee maksimal kepada agen Branchless Banking Rp 7.500 untuk transaksi yang 
dilakukan. Agen Branchless Banking yang direkrut BTPN memiliki sejumlah syarat yakni merupakan nasabah BTPN yang memiliki usaha, misalnya penjual pulsa. BTPN menempatkan staff Agen tidak bisa ditinggal sendiri. Satu staf representatif kami akan mengawasi satu area yang berisi 50 agen. Tugas agen nantinya melakukan edukasi ke masyarakan. Untuk setiap setoran yang dilakukan, nasabah tidak akan dikenakan biaya transaksi. Namun, apabila nasabah melakukan penarikan dana, maka akan dikenakan biaya. Sebaiknya juga agen bank cukup dikenal masyarakat setempat, highly educated dan tidak memiliki likuiditas baik. Sejauh ini belum ada permasalahan yang berkaitan dengan branchless banking. OJK mewajibkan Bank penyelenggara untuk menerapkan manajemen resiko, untuk menghindari hal-hal yang tidak diinginkan bagi agen banking.Tidak begitu banyak perbedaan persayaratan sebelum diambil alih OJK ataupun sesudahnya.

BTPN yang ada di kota Medan, memang satu-satunya bank penyelenggara branchless banking yang begitu terbuka terhadap informasi ini. Agen banking BTPN begitu mudah untuk dikenali dengan tulisannya yang cukup mencuri perhatian "AGEN BTPN WOW' di spanduk-spanduk yang tertera di depan ruko, warung atau tempat lainnya. Sehingga masyarakat cukup mudah untuk mendapatkan layanannya, cukup mudah dan praktis untuk menjadi pengguna Branhless banking., walau tanpa menyetor uang pada saat itu, walaupun tanpa dana Anda bisa mendaftarkan diri Anda untuk menjadi nasabahnya. Dan yang lebih praktis lagi selain tanpa harus memiliki saldo rekening sedikitpun, nasabah tidak perlu repot menghapal nomor rekening, cukup dengan nomor HP Anda yang aktif, karena nomor seluler secara otomatis akan menjadi nomor rekening. Sehingga tidak perlu takut lupa, sangat mudah dan cepat. Dan yang pasti dapat melakukan transaksi keuangan apapun, tanpa harus ke Bank untuk mendaftar dan tanpa takut tidak memiliki dana. Masyarakat tidak perlu capek berlama-lama menunggu di Bank untuk melakukan transaksi keuangan, karena proses layanannya yang sangat cepat.

Dengan penjelasan di atas jelas bahwa masyarakat cukup dimudahkan untuk menjadi masyarakat bankable, masyarakat tidak perlu sungkan untuk berhubungan dengan pihak Bank, tidak 
perlu takut dengan biaya-biaya yang tidak perlu kita keluarkan, karena walaupun bertransaksi melalui pihak ketiga yakni agen banking, bank tetap konsisten untuk tidak membebankan biayabiaya yang begitu menyulitkan masyarakat. Melalui agen banking juga , masyarakat menjadi lebih nyaman untuk bertransaksi, dengan lokasi yang dekat dengan tempat tinggalnya, orang yang cukup dikenalnya akan membuat si nasabah lebih nyaman untuk berkomunikasi apapun yang ingin didiskusikannya, berbeda dengan jika masyarakat berada di Bank dengan ruang AC dan tempat yang terkesan mewah, yang membuat si nasabah tidak memiliki keberanian untuk memasukinya. Sehingga peran agen banking untuk mencapai masyarakat bankable di Indonesia akan tercapai. Dan akan lebih cepat tercapai jika peran dari agen banking yang pro aktif diperbanyak dan ditingkatkan.

Dengan demikian segala perannya dan kedekatannya kepada masyarakat membuat agen banking mudah diterima di masyarakat umum. Berbeda dengan pihak Bank yang masih memiliki jarak dengan pihak Bank, namun agen banking justru sebaliknya Mereka adalah orang-orang yang sangat dekat dengan masyarakatnya. Kebijakan branchless banking akan memungkinkan bank menjangkau unbanked people dan masyarakat di remote area untuk menerima layanan perbankan. Lebih jauh, kebijakan multilicense dan branchless banking akan mampu bersinergi untuk mendorong efisiensi operasional serta dapat meningkatkan penyaluran kredit bagi UMKM sekalgisu memudahkan bank memnuhi kewajiban untuk menyalurkan kredit UMKM sebesar $20 \%$.

\section{Kendala dan Resiko Agen Banking}

Agen banking yang berada di kota Medan ini juga memiliki kendala yang cukup tinggi, terutama kepercayaan dan keamanan. Termasuk juga dalam meningkatkan jumlah pemakainya, mengingat sebahagian masyarakat masih malas berhubungan dengan bank, karena khawatir biaya yang tinggi, termasuk potongan dalam mengambil tabungan. Jika agen banking melakukan kekeliruan ataupun hal lainnya yang bisa menghilangkan kepercayaan para penggunanya apalagi bank penyelenggara. Namun jika agen banking benar-benar mampu dipercaya tentunya amat mudah 
untuk menarik menjadi nasabah bank terkait. Sehingga para agen banking sangat khawatir jika di dalam melakukan transaksi, prosesnya terlalu lama diakibatkan jaringan bermasalah, apalagi di dalam melakukan transaksi penyetoran. Karena seringnya mati lampu dan gangguan listrik lainnya serta signal yang buruk membuat transaksi kadang terkendala, yang membuat nasabah marah dan kecewa. Untuk itu para agen banking berharap agar bank penyelenggara tetap memberikan perhatiannya yang serius terhadap jaringan telekomunikasi agar lebih baik. Belum lagi terpaan isu kuat tentang bank si agen banking yang negatif, sehingga bisa menyurutkan motivasi si agen banking untuk menjalankan bisnisnya. Mereka menjadi cenderung pasif, diam ditempat, karena kadang-kadang terpaan isu datang dari agen banking beda bank ini. Sangat disayangkan persaingan ini menjadi cenderung terkesan tidak profesional . Untuk menghindari hal ini, agen banking diminta untuk tidak terpancing oleh isu-isu negatif yang dilontarkan pihak lain. Dan tetap menjalankan bisnisnya seperti biasa. Cara lain adalah sebaiknya ada tim pengawas agen banking, agar jika ada hal-hal negatif dapat diatasi sejak dini. Namun sepertinya dari survey terlihat BTPN kekurangan SDM dalam melakukan monitoring. BTPN sebaiknya menambah personil untuk melakukan pengawasan ini, dan juga untuk menambah jumlah agen banking, dapat membentuk Tim untuk merekrut agen banking baru. Disisi lain para Agen banking khususnya agen keliling diharuskan pro aktif melakukan "jemput bola" ke rumah masyarakat untuk membantu membuka rekening, transfer dana, setor ataupun tarik tabungan, agar semakin cepat tujuan pemerintah dalam mencapai bankable, dan tentunya semakin tinggi jumlah nasabah yang direkrut.

Sebenarnya peminat masyarakat yang ingin menjadi agen banking di Medan cukup tinggi, namun di satu sisi para agen banking merasa tidak mudah untuk meyakinkan pedagang lain dan pengunjung tokonya agar mau menjadi nasabah nya khususnya nasabah tabungan. Salah satu penyebabnya adalah nasabah tidak mendapatkan buku tabungan fisik yang lazim diberikan bank reguler dan transaksi dilakukan lewat ponsel. Sehingga cara ini masih asing di kalangan pedagang termasuk masyarakat pada 
umumnya. Selain itu, pola bisnis ini mengandung risiko, terutama menyangkut aksi kejahatan. Agen yang harus menghadapi risiko tersebut, karena agen bakal memegang uang tunai ketika melayani transaksi pembelian pulsa listrik dan ponsel, transfer uang, dan setoran tabungan. Apalagi kini kejahatan di masyarakat semakin tinggi, ini juga yang dialami para agen banking di kota Medan. Para Agen banking ini sebenarnya memiliki resiko yang cukup besar karena mereka harus membangun kepercayaan nasabah Sementara bank tidak menghadapi risiko kehilangan uang lantaran transaksi keluar masuk uang akan didebit atau dikredit dari rekening milik si agen di bank tersebut. Walaupun sejauh ini belum ada laporan tentang hal-hal negatif tentang agen banking di kota Medan.

\section{Simpulan}

Dari penjelasan dan pembahasan di atas dapat diambil kesimpulan sebagai berikut:

1. Branchless banking adalah inovasi layanan perbankan terbaru non konvensional, yang diluncurkann untuk meningkatkan layanan keuangan kepada masyarakat khususnya masyarakat kelas bawah atau masyarakat yang tinggal di pelosok-pelosok desa, dengan tanpa melalui kantor fisik Bank.

2. Kehadiran agen Branchless Banking masih cukup awam oleh masyarakat Medan, jadi masih jauh dari yang diharapkan pemerintah, salah satu penyebabnya minimnya sosialisasi dari pemerintah dan termasuk juga bank penyelenggara. Padahal potensinya sangat tinggi, dimana kedepannya segala kendala yang ada dalam melakukan transaksi bisa diatasi dengan adanya branchless banking

3. Para agen banking menghadapi kendala, resiko yang cukup tinggi dalam bisnis ini,baik itu kepercayaan dari masyarakat maupun kejahatan di lapangan, namun sejauh ini masih belum ditemukan hal-hal negatif tentang agen banking di kota Medan.

4. Agen banking mampu mencapai masyarakat bankable, mengingat para agen banking langsung berhubungan dengan masyarakat, mudah dalam bertransaksi dan mudah 
dijangkau, serta tidak terlalu formal, dengan dana awal yang cukup terjangkau.

5. Bertransaksi dengan agen banking cukup aman, karena dari laporan OJK sampai saat ini belum ada satupun laporan yang masuk tentang agen banking, ini berarti bertransaksi dengan agen banking benar-benar aman.

6. Agen banking khususnya agen keliling diharuskan pro aktif melakukan "jemput bola" ke rumah masyarakat untuk membantu membuka rekening, transfer dana, setor ataupun tarik tabungan, agar semakin cepat tujuan pemerintah dalam mencapai bankable.

7. Minimnya SDM untuk pengawasan terhadap agen banking khususnya untuk memonitoring layanan baru, termasuk dalam mencari agen banking baru dan nasabah. 


\section{DAFTAR PUSTAKA}

\section{Buku}

D.L. Morgan and R.A. Kruger (1993) When to Use Focus Group and Why, , in ed. D.L. Morgan Successful Focus Groups, pp.

Hidayat, syah (2010) Pengantar Umum Metodologi Penelitian Pendidikan Pendekatan Verivikatif. Pekanbaru, Suska Press Irwanto 1998 Focus Group Discussion, Pusat Kajian Pembangunan Masyarakat

Hidayat syah.2010.Pengantar Umum Metodologi Penelitian Pendidikan Pendekatan Verivikatif. Pekanbaru : Suska Pres.

Moleong, Lexy J (2007) Metodologi Penelitian Kualitatif: Bandung $>$ Rosda.cet $/ 24$

Punaji Setyosari (2010) metode Penelitian Pendidikan dan Pengembangan, Jakarta : Kencana

Silalahi, Ulber. (2006). Metode Penelitian Sosial. Bandung: Unpar Press.

Sugiyono, Memahami Penelitian Kualitatif, (Bandung: AlfaBeta, 2012), cet. 1

Bungi, Burhan, Analisa Data Penelitian Kualitatif, (Jakarta: Raja Grafindon, 2003), cet. 1

Sukardi.2003.Metodologi Penelitian Pendidikan. Jakarta : Bumi Aksara.

Suratno, Metode Penelitan Kualitatif , makalah Seminar Metodologi Penelitian Program Pascasarjana IAIN Antasari Banjarmasin, Tanggal 05 April 2010.

Tanuwidjaja, William. (2009). 8 Intisari Kecerdasan Finansial. Yogyakarta: Media Pressindo . (2013). Layanan Keuangan Digital (Digital Financial

Service). Diambil dari Kantor Perwakilan Bank Indonesia Malang

\section{Jurnal}

Amabile, M. Teresa (1997), 'Motivating Creativity in Organizations: On Doing What You Love and Loving what You Do", California Management Review, Vol.40,No. 1, p.39-58. 
Agen Branchless Banking Untuk Mencapai Masyarakat Bankable

Mulyono,F. (2008). "Inovasi: Sebuah Pengantar". Jurnal Ilmu Administrasi Bisnis. Rahmani, E. (2006) "Mengelola Kemampuan Teknologi untuk Mencapai Keunggulan Bersaing".

Porter, S.S., Claycomb, C. 1997. The Influence of Brand Recognation on Retail Store Image. Journal of Prod. Brand Management.

Pungky Purnomo Wibowo (2013), Branchless Banking setelah multilicense Ancaman atau Kesempatan Bagi Perbankan Nasional Bank Indonesia

Repository jurnal Universitas Sumatera Utara. (Online). http:// repository.usu.ac.id Literacy Dan Financial Behavior Mahasiswa Strata I Fakultas Ekonomi Universitas Sumatera Utara.

Schilling, M.A., and Hill, C.W.L (1998), "Managing the New Product Development Process: Strategic Imperatives", Academy of Management Executive, Vol.12 (3), Agust,pp.67-81.

Suhartini, Dwi dan Jefta Ardhian Renata. (2007).Pengelolaan Keuangan Keluarga Pedagang Etnis Cina. Jurnal Riset Ekonomi dan Bisnis, Volume 7,Nomor.2.

Tim Stapleton, (2013), The Transformative Potential of Branchless Banking in Indonesia, Bulletin of Indonesian Economic Studies No.49, No.3, 2013, 355-80, Unlocking .

ISSN 0007-4918 print/ISSN 1472.7234 online/13/030355-26

http :/ / dx.doi.org/10.1080/000749182013.850633

2013 Indonesia Project ANU

Weerawardena, J. (2003). “Exploring The Role of Market Learning Capability in Competitive Strategy". European Journal of Marketing. diakses dari http:// proquest.com pada tanggal 12 November 2013.

Widayati, Irin. (2012). Faktor-faktor yang Mempengaruhi Literasi

Finansial Mahasiswa Fakultas Ekonomi Dan Bisnis Universitas Brawijaya. Jurnal Akuntansi dan Pendidikan, Volume 1, Nomor 1.

Internet

Bambang Priyo Jatmiko, (2015), http:// bisniskeuangan.kompas. $\mathrm{com} / \mathrm{read} . .$. 
015 / 03 / $30 / 135439326$ / Bank. Bakal.Tak.Butuh.Banyak. Pegawai?utm_campaign=related $\& u t m \_m e d i u m=b p-$ kompas\&utm_source=bisniskeuangan\&

Bank Indonesia. (2014). Booklet Keuangan Inkusif Bank Indonesia. Dikutip dari Bank Indonesia. (Online)

http://www.bi.go.id/id/perbankan/keuanganinklusif/edukasi/ Pages/Booklet-Keuangan-Inklusif.aspx

BNI Securities (2010) Diambil dari bnisecurities.com diakses pada 5 Maret 2015 http://bnisecurities.co.id/2013/10/bipenerapan-branchless-banking-masih-ada-kendala/

BTPN Wow. Blogspot, (2015_), http:/ / BTPNwow.blogspot.co.id/

BTPN COM http://www.btpn.com/berita-and-media/ulasankhusus/btpn-wowjembatan-untuk-unbanked-people/

Budiman, Syahrul Dikutip dari akademia.edu (Online) diakses pada 4 Maret 2015 http://www.academia.edu/5562212/ PengolahandanAnalisisDataKualitatif

Damayanti. (2014). Literasi Keuangan Indonesia Terendah se-Asia Pasifik. (Online). http://analisadaily.com diakses pada 17 Agustus 2014

Devie Kania/HS ,Investor Daily, http://www.beritasatu. com/bank-dan-pembiayaan/309010-2019-bi-sasar-50masyarakat-dilayani-bank.html Selasa, 22 September 2015 | 18:46

Fachrudin, Yudhi (2013) Dikutip dari akademia.edu diakses pada 3 Maret 2015 http://www.academia.edu/5765488/Analisis_ Penelitian_Kualitatif,

Fatimah, Nur (2013). Penelitian Deskriptif. Diambil dari blogspot.com (Online) diakses pada 3 Maret 2015 http:// nurfatimahdaulay18.blogspot.com

Informasi Pendidikan, (2013) Dikutip dari informasipendidikan. com diakses pada 5 Maret 2015 http://www.informasipendidikan.com/2013/08/ penelitian-deskriptif-kualitatif. html 
Jaya, Alit Asmara dan Gusti Ngurah. (2013). Kenapa Branchless Banking. (Online). http://branchlessbkg.blogspot.com/ diakses pada tanggal 17 Agustus 2014

Kementerian Keuangan. (2013). Strategi Nasional Keuangan Inklusif. Diambil dari Kementerian Keuangan RI. (Online). www.fiskal.depkeu.go.id

KeuanganiInvestasi.blogspot.(2015)http:/ / keuanganinvestasi. blogspot.co.id/2015/02/bank-mandiri-tawarkan-bisnisagen-bank.html

Kusuma, Dewi Rachmat. (2014). Melek Keuangan Masyarakat Indonesia Masih di Bawah Singapura dan Malaysia. (Online). http:/ / finance.detik.com diakses pada 13 Agustus 2014

Limbong, Apriliana. (2014). Masuk Kelompok G-20 itu Tidak Mudah, Kawan!. (Online). http://politik.kompasiana.com diakses tanggal 23 Mei 2014

Nababan, Darman dan Isfenti Sadalia. (2013). Analisis Personal Financial Wiyanti, Sri. (2013). BI: Agen Bank Harus Dikenal Masyarakat. (Online). http://www.merdeka.com diakses pada tanggal 13 Agustus 2014

Roswati, Sri (2014) Dikutip dari tempokini.com, diakses pada 5 Maret 2015 http://www.tempokini.com/2014/11/4964/ 3 maret 2015

Rushandie, Robby (2014) Dikutip dari kompasiana.com, diakses 3 Maret 2015 http://ekonomi.kompasiana.com/ moneter / 2014/10/30/branchless-banking-lebih-darisekedar-jargon-marketing-683535.html

Setiawan, Moch. Agung (2014) Dikutip dari blogspot.com diakses 4 Maret 2015 http://moh-angscorp2.blogspot.com/2014/08/ financial-inclusion-banchless-banking.html

Setiawan, Sakina R. Dian (2013) Dikutip dari kompas.com diakses 5 Maret 2015 http://bisniskeuangan.kompas. com/read/2013/10/09/1259440/BI.Branchless.Banking. Terkendala.Sinyal.Telekomunikasi.Lemah

Setyobudi, Wahyu T. (2010). Teknik Moderasi Focus Group Discussion (FGD). Diakses pada tanggal 25 Desember 2011, dari:http:// 
inspirewhy.com/teknik-moderasi-focus-group-discussionfgd

Supartoyo, Yesi Handriani dan Kasmiati. (2013). Branchless Banking Mewujudkan Keuangan Inklusif sebagai Alternatif Solusi Inovatif Menanggulangi Kemiskinan: Review dan Rekomendasi. Dikutip dari academia.edu (Online) https:// www.academia.edu

Sulistiyana, Eka (2013) Dikutip dari ekasulistiyana.web.id diakses 3 Maret 2015 http://www.ekasulistiyana.web. id/artikel/kuliah/branchless-banking-salah-satu-upayamensukseskan-financial-inclusion/

Sulistiyana, Eka (2012) Dikutip dari ekasulistiyana.web.id diakses 4 Maret 2015 http://www.ekasulistiyana.web.id/kuliah/ bahan-kuliah/financial-inclusion-sebuah-konsep-danpemahaman-sederhana/

Yulianti, Tya Eka. (2013). Bappenas: Baru 20 Persen Penduduk RI Punya Tabungan di Bank. (Online). http://finance.detik. com diakses pada 13 Agustus 2014

Yusharto, Irma. (2014). Branchless Banking sebagai Terobosan Inklusi Finansial (Tulisan untuk memperkaya perbankan di Indonesia). Dikutip dari academia.edu (Online) https:// www.academia.edu

Team, Marketing Com. (...) Dikutip dari lintasarta.net diakses pada 3 Maret 2015 http://www.lintasarta.net/OurCompany/ NewsandMedia/News/tabid/407/aid/466/language/enUS/Default.aspx

Wibawanti, N Adi (2013) Dikutip dari infobanknews.com diakses 4 Maret 2015 http:/ / www.infobanknews.com/2013/09/inikendala-branchless-banking-di-indonesia/ 